\title{
Brucella ovis: invasão, tráfego, fatores de virulência e resposta imune
}

\author{
Brucella ovis: \\ invasion, traffic, virulence factors and immune response
}

\author{
João Marcelo Azevedo de Paula Antunes ${ }^{1}$; Jane Megid²* $^{2 *}$
}

\section{Resumo}

\begin{abstract}
A brucelose permanece como problema econômico em animais e de saúde pública. Em todo o mundo a brucelose ovina ocasionada pela Brucella ovis é considerada uma das principais causas de infertilidade em ovinos. Os fatores responsáveis pela persistência do agente não são conhecidos, bem como os mecanismos imunes envolvidos na defesa e eventualmente na persistência do agente. Brucella spp. induz resposta inflamatória moderada. A natureza intracelular do agente estimula resposta imune celular do tipo linfócito T helper 1. Os estudos de patogenia da brucelose ovina são escassos. Recentes avanços demonstraram que a resposta inflamatória moderada induzida pelas brucelas representam provavelmente o resultado de tentativa de escape da resposta imune e supressão da resposta imune hospedeira. Foram revisados os mecanismos descritos pelas brucelas e pela Brucella ovis para penetração no hospedeiro, escape da resposta imune, bem como a resposta imunológica gerada pela infecção.

Palavras-chave: Brucelose, patogenia, imunopatologia, Brucella ovis
\end{abstract}

\begin{abstract}
Brucellosis remains an economic problem in animals and public health. Worldwide ovine brucellosis caused by Brucella ovis is considered a major cause of infertility in sheep. The factors responsible for persistence of the agent are not known, as well as the mechanisms involved in immune defense and possibly the persistence of the agent. Brucella spp. induces moderate inflammatory response. The nature of the intracellular agent stimulates immune response of the type 1 helper T lymphocytes. Studies of the pathogenesis of ovine brucellosis are scarce. Recent developments have shown that the inflammatory response induced by moderate brucelas represent probably the result of an attempt to escape the immune response and suppression of host immune response. Were reviewed by the mechanisms described by brucelas and Brucella ovis for penetration into the host, escape of the immune response and the immune response generated by the infection.
\end{abstract}

Key words: Brucellosis, pathogenesis, immunopathology, Brucella ovis

\footnotetext{
1 Discente da Faculdade de Medicina Veterinária e Zootecnia, FMVZ, Universidade Estadual Paulista, UNESP, Botucatu, SP. E-mail: joaomarceloantunes@live.com

2 Prof $^{a}$. da FMVZ/UNESP, Botucatu, SP. E-mail: jane@fmvz.unesp.br

* Autor para correspondência
} 


\section{Introdução}

A brucelose é uma doença infecto-contagiosa crônica comum a diversas espécies animais causada por cocobacilos Gram-negativos do gênero Brucella. Brucelas são bactérias patógenas dos mamíferos e são fortemente relacionadas com outros parasitas intracelulares da classe a-Proteobacteria e gênero Orchrobactrum como Bartonella, Rickettsia, Anaplasma e Wolbachia (ETTEMA;ANDERSSON, 2009).

Mundialmente a brucelose permanece como problema econômico na criação de animais domésticos (NOZAKI et al., 2004; LIRA, 2008; NOZAKI, 2008) e de saúde pública, com aproximadamente 500.000 casos por ano na espécie humana (TALESKI et al., 2002). Atualmente, são reconhecidas seis espécies do gênero Brucella: $B$. melitensis, B. abortus, B. suis, B. neotomae, B. ovis e B. canis (LOPEZ; BEST; MORALEZ, 1998), além de novas espécies em animais marinhos classificadas, previamente, como B. cetaceae e B. pinnipediae (FOSTER et al., 2002). Novas espécies de brucelas foram isoladas de animais selvagens (B. microti) (SCHOLZ et al., 2008), de implante de mama (SCHOLZ et al., 2010) e de pneumonia (TILLER et al., 2010), esta última denominada $B$. inopinata. As espécies clássicas mostram preferências por diferentes hospedeiros, mesmo exibindo $98 \%$ de homologia em seu DNA
(FERRAZ, 1999; NOZAKI et al., 2011a). Seis das dez espécies de Brucella (B. melitensis, B. abortus, $B$. suis, B. canis, B. ceti e B. pinnipedialis) têm potencial zoonótico (TILLER et al., 2010).

A brucelose ovina é reconhecida como a mais importante causa de epididimite, sendo uma das principais causadoras de infertilidade em ovinos (RIDLER; WEST, 2011, NOZAKI et al., 2011b). Embora encontrada em vários órgãos, B. ovis causa lesão específica em órgãos do trato reprodutivo masculino. Os fatores responsáveis pela persistência do agente nos órgãos reprodutivos não são conhecidos, bem como os mecanismos imunes envolvidos na defesa e eventualmente na persistência do agente (GIL-TURNES, 1998; TSOLIS et al., 2009).

Lira e Megid (2009), relatando que estudos sobre a brucelose ovina ainda são escassos, afirmaram que o conhecimento da patogenia da infecção dos ovinos pela $B$. ovis poderá reduzir a ocorrência de prejuízos econômicos aos criadores dessa espécie animal. Recentes avanços demonstraram que o gênero Brucella induz apenas uma resposta inflamatória moderada que resulta provavelmente da evasão e supressão da resposta imune do hospedeiro susceptível (XAVIER et al., 2010; ANTUNES et al., 2013). Neste trabalho de revisão serão apresentados os mecanismos utilizados pela $B$. ovis, para invadir o hospedeiro e para proteger-se de sua resposta imune (Figura 1).

Figura 1. Aderência, internalização, tráfego intracelular, fatores de virulência e resposta imune induzida pela $B$. ovis em um macrófago infectado. Todos os mecanismos relacionados a invasão de $B$. ovis não interrompem o processos básicos da célula do hospedeiro. O objetivo da B. ovis é alcançar o RE e multiplicar. A bactéria penetra no ovino pelas mucosas conjuntival, retal e prepucial ou por pele lesionada. Macrófagos e neutrófilos são as primeiras células de defesa contra B. ovis. B. ovis possui a capacidade de infectar células fagocíticas (macrófagos, células dendríticas) e não fagocíticas (epiteliais, trofoblásticas, células do sistema respiratório e neurônios). 1- Aderência: os PAMPs bacterianos aderem a célula do hospedeiro reconhecendo os receptores de ácido siálico, resíduos sulfatados, PRRs (LFA-1, CR3, integrinas, MPR, receptores Fc), TLRs, NODs e LBP mediando a aderência/internalização, resultando em: opsonização, endocitose, fagocitose e trancrição de genes da RI inata. Fatores de virulência da fase 1: Omp25 (responsável por aderência, replicação e sobrevivência); 2- Internalização: realizada principalmente pelos receptores de colesterol e gangliosídeo GM1 classe A "scavenger"; Fatores de virulência fase 1 e 2: BvrR/BvrS- regulam a expressão das Omp e é requerido para recrutar GTPases e filamentos de actina, evitam a fusão do BCV com o lisossomo, mutantes BvrR/BvrS são incapazes de penetrar na célula; 3- Tráfego: dentro da célula a brucela utiliza o citoesqueleto de actina/microtúbulos para o tráfego intracelular com ativação de GTPases (Rho, Rac, Cdc42) que modulam a 
invasão para translocar as vesículas dentro da célula. Tyr-K (tirosina quinase), PIP3-K (fosfoinositol-3 quinase) atuam como segundos mensageiros dos sinais das GTPases no processo de internalização e tráfego; 4- Brucellassomos tardios: marcados com LAMP-1 e acidificados onde a bactéria funde com o lisossomo, resultando o fagolisossomo (marcado com catepsina D) que realiza a produção de óxido nítrico para eliminação das brucelas (5), nesta fase dentro do fagolisossomo a brucela pode sobreviver devido a expressão do fator de virulência T4SS que inibem a explosão respiratória; Fatores de virulência fase 4 e 5: T4SS (virB) aparato de transporte localizado na Omp capaz de translocar DNA bacteriano/proteínas no interior da célula hospedeira, tráfego do BCV até o nicho de replicação; virB mutantes não atingem o RE; 6- BCV precoces: estas vesículas estão marcadas com Rab5 e EEA1 permitindo sua sobrevivência; 7- BCVs se fundem com os RE que estam marcados com calnexina e multiplicam-se podendo lesar

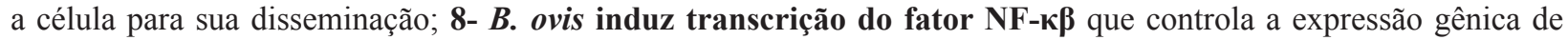
citocinas. Nesta fase $B$. ovis inibe sinais via TLRs, que por cascata inibem maturação de $\mathrm{CD}$, citocinas inflamatórias, inibem apoptose, induzem necrose de macrófagos, afetando a RI; 9- B. ovis compromete a produção de TNF- $\boldsymbol{\alpha}$, que bloquea a produção de IL-12 e INF- $\gamma$ inibindo a RIC (Th1) citotóxica promovendo uma evasão da RI e prolongando sua vida intracelular (persistência). M- marcadores; FV- fatores de virulência; RE- retículo endoplasmático; BCVbrucellas containing vacuoles; CD- células dendríticas; BvrR-BvrS- sistema regulatório de dois componentes; PRRs- pattern recognition receptors; LFA-1- leucocyte function-associated antigen 1; CR3- complement receptor 3; integrinas alpha-5, beta-1 e beta-3, MPR- receptores de manose-6-fosfato; PAMPs- pathogen-associated molecular pattern; NODs- nucleotide-binding oligomerization domain proteins; LBP- lipopolysaccharide binding protein; RI- resposta imune; Rab5- GTP-binding protein rab5; EEA1- antígeno endossomal precoce 1; LAMP 1- proteínas associadas a membrana lisossomal 1; T4SS ou gene virB- sistema de secreção tipo-IV; RIC- resposta imune celular; Th1- linfócitos T helper 1; NK- natural killers; PMN-polimorfonucleares.

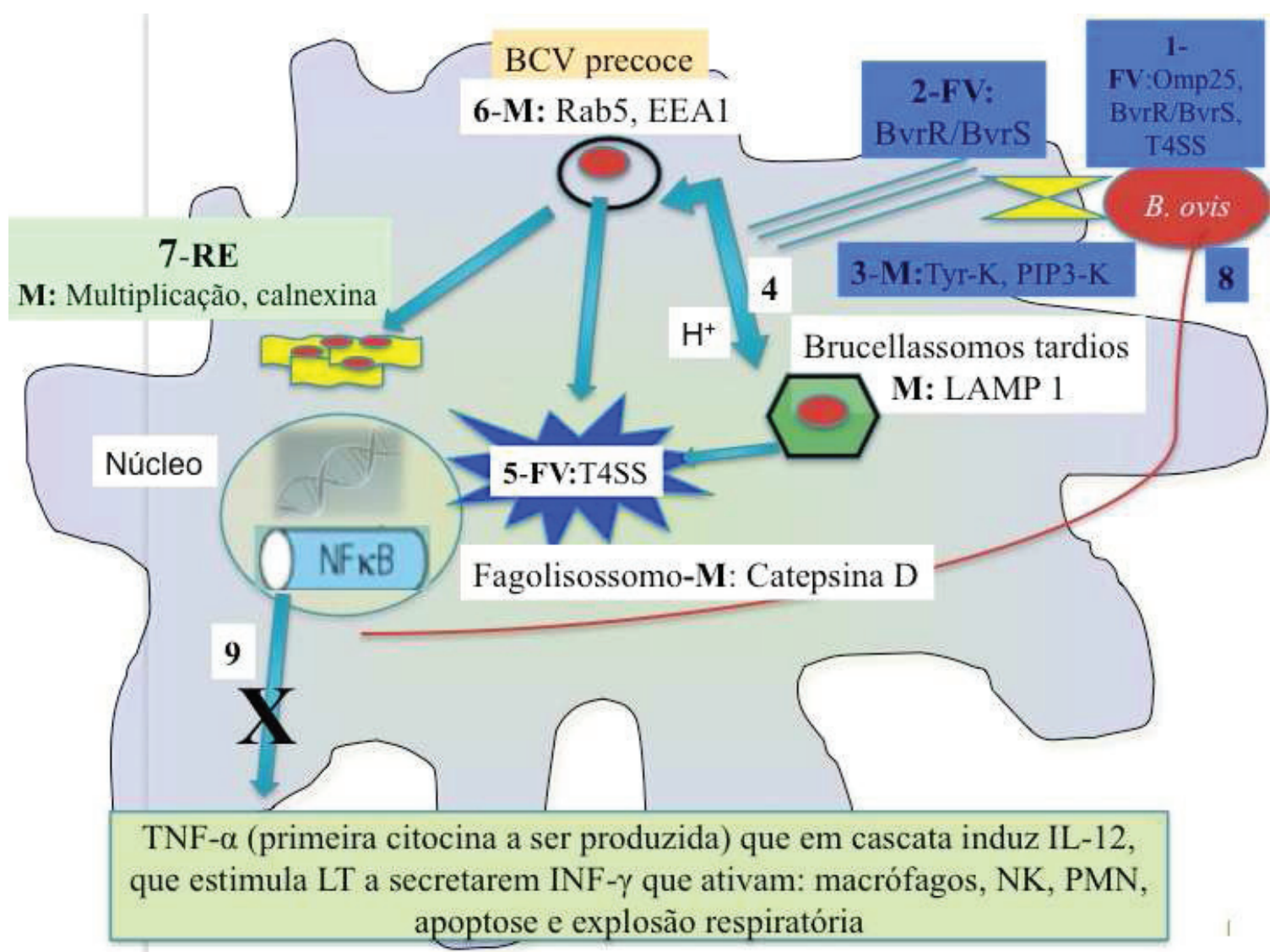

Fonte: Elaboração dos autores. 


\section{Revisão Bibliográfica}

Brucella pode ser definida como microrganismo intracelular-extracelular facultativo (GORVEL; MORENO, 2002). Os verdadeiros elementos de virulência da Brucella spp. são os determinantes moleculares que permitem a bactéria invadir, resistir a morte e se replicar em células fagocitárias profissionais e não profissionais (GUZMÁNVERRI et al., 2001). As brucelas lisas inibem a apoptose da célula hospedeira, enquanto que as rugosas tais como $B$. ovis induzem a necrose do macrófago (PEI et al., 2006). Seleem, Boyle e Sriranganathan (2008), referiram que as brucelas não possuem os genes clássicos de virulência, e sim fatores de virulência que evitam a resposta imune e aumentam sua sobrevivência.

A B. ovis inicialmente coloniza os linfonodos regionais da porta de entrada e a, seguir por volta dos 30 dias da infecção, por bacteremia, acaba por atingir os órgãos do trato genital (LIRA, 2008; NOZAKI et al., 2008). Os fatores que definem o tropismo pelo trato genital ainda não foram totalmente esclarecidos (BIBERSTEIN et al., 1964). As estratégias que impedem a detecção das brucelas pelo sistema imune do hospedeiro infectado incluem: infecção intracelular prolongada com modificação da expressão dos genes, sobrevivência em vesículas acidificadas, alteração da apoptose de macrófagos, com bloqueio da fusão do fagolisossomo com redução da ativação dos mecanismos de proteção e da inflamação (RAJASHEKARA et al., 2006).

\section{Aderência e penetração}

As linhagens de Brucella spp. podem ser lisas ou rugosas, dependendo da presença ou ausência da cadeia de polissacarídeo $O$ na molécula de lipopolissacarídeo (LPS). Linhagens como $B$. ovis não possuem a cadeia $\mathrm{O}$. Assim a cadeia de polissacarídeo $\mathrm{O}$ não recobre outros antígenos da superfície como os das outer membrane proteins (OMPs), deixando-os mais expostos. $\mathrm{O}$ antígeno 29-kDa é composto por duas OMPs, a Omp25 e a
Omp31 (VISCAÍNO et al., 2001). Destes, a Omp25 está diretamente envolvida na invasão, replicação e sobrevivência da $B$. ovis no interior de células hospedeiras (CARO-HERNÁNDEZ et al., 2007; MARTÍN-MARTÍN et al., 2008). A invasão celular ocorre por receptores de moléculas contendo ácido siálico ou resíduos sulfatados, poucos minutos após a aderência nas células alvos (CASTANEDAROLDAN et al., 2004).

Martín-Martín et al. (2010) demonstraram que a infecção por $B$. ovis em macrófagos utiliza receptores de superfície comuns a Brucella spp. lisas o que limita a ativação de macrófagos e favorece a a sua sobrevivência e replicação intracelular . Esta infecção é dependente de dois componentes dos lipídeos que internalizam a bactéria, denominados de receptores de colesterol e o gangliosídeo GM1 classe A "scavenger". Após a internalização as brucelas, são endocitadas por macrófagos regionais e transportadas para linfonodos regionais da porta de entrada. Caso as bactérias não sejam eliminadas neste estágio ocorrerá a sua disseminação pelo sistema mononuclear fagocitário (SMF). no qual ocorre a sua multiplicação (GORVEL; MORENO, 2002).

O mecanismo exato utilizado para a internalização das brucelas nas células do SMF ainda é desconhecido. Entretanto, as evidências atualmente disponíveis admitem que a função da expressão das células do sistema imune inato com os seus receptores padrões de reconhecimento (PRRs), incluindo LFA-1 (leucocyte functionassociated antigen 1), complement receptor 3 (CR3), integrinas alpha-5, beta-1 e beta-3, receptores de manose-6-fosfato (MPR) e receptores Fc reconhecem os PAMPs (pathogen-associated molecular pattern) do patógeno e possibilitam a sua aderência e internalização (CAMPBELL; ADAMS; SOWA, 1994). Após os PAMPs serem reconhecidos pelos PRRs ocorre a opsonização, endocitose e fagocitose da bactéria e inicia-se a transcrição dos genes da resposta imune não específica. Os produtos destes genes incluem peptídeos antimicrobianos 
(GANZ; LEHRER, 1998) e citocinas inflamatórias (BARNES; LUBYOVA; PITHA, 2009).

Após a aderência das brucelas nos macrófagos do hospedeiro, o citoesqueleto de actina e microtubulos participam da internalização das Brucellas. No interior da célula ocorre ativação de GTPases da família Rho (Rho, Rac e Cdc42), proteínas envolvidas em diversos processos celulares, que permitem a modulação da invasão pelas brucelas. Sabe-se que os components BvrS e BvrR que estão envolvidos na homeostase estrutural das proteínas externas de membrana (OMP3a e OMP3b), quando inativados são incapazes de ativar $\mathrm{Cdc} 42$ ficando a B. abortus incapaz de invadir as células. Brucelas BvrR/BvrS null mutantes são incapazes de ativar Cdc42 small GTPase, então são incapazes de invadir células, permanecendo ligadas na superfície celular do hospedeiro (GUZMÁN-VERRI et al., 2001). Uma falha na eliminação da Brucella spp. após a sua internalização nos macrófagos e transporte para os linfonodos leva a sua disseminação para os órgãos e linfadenopatia regional (ENRIGHT, 1990). As brucelas opsonizadas ligam-se as células fagocitárias profissionais através do complemento e receptores $\mathrm{Fc}$, enquanto que em células não fagocitárias a ligação é efetuada via lecitina e fibronectina (RITTING et al., 2001).

\section{Tráfego intracelular e replicação}

Dentro da célula do hospedeiro o nicho intracelular das brucelas incluem os fagossomos precoces denominados "brucellas containing vacuoles" (BCVs) e os fagossomos tardios acidificados especializados dos macrófagos, chamados de brucellassomos. Após a internalização da Brucella spp., o BCV precoce que é bem justo será o compartimento que permitirá a sobrevivência da bactéria, enquanto que o brucellassomo tardio que se apresenta mais espaçoso, será o compartimento da eliminação da bactéria (RITTING et al., 2001). Os BCVs acidificam mas falham em acumular MPR e catepsina D como marcadores de BCVs tardios. Em seguida, os BCVs se fundem-se com o retículo endoplasmático $(\mathrm{RE})$ e proteínas como calrreticulina e calnexina, onde a Brucella spp. pode se replicar. As brucelas replicam em compartimentos semelhantes ao RE e lisam a célula hospedeira para sua disseminação (QIN et al., 2008). Uma vez dentro do fagossomo sobrevivem a explosão respiratória e ao ambiente adverso através da interação com o sistema de secreção tipo-IV (T4SS ou virB) com o retículo RE do hospedeiro (CELLI; CHASTELLIER; FRANCHINI, 2003). O sistema T4SS codificado pelo gene virB controla o tráfego intracelular e evita sua degradação inibindo a fusão fagossomo-lisossomo (COMERCI et al., 2001).

O retardo da fagocitose é o tempo necessário para $B$. abortus modificar a membrana plasmática da célula criando uma organela que possibilita a sobrevivência e replicação intracelular (BELLAIRE; ROOP; CARDELLI, 2005). Muitas brucelas são eliminadas pelos fagolisossomos dos macrófagos. Entretanto, as que impedem a fusão lisossomal são capazes de se multiplicar amplamente durante o tráfego intracelular (GORVEL; MORENO, 2002). Após poucos minutos da invasão a $B$. abortus interage com compartimentos intracelulares relacionados com a rede endossomal precoce, confirmada pela presença de marcadores como receptores de transferrina, pequenas GTP-binding protein rab5 ou o antígeno endossomal precoce 1 (EEA1). Os fagossomos ou BCVs precoces gigantes contendo bactérias marcadas com Rab5 permitem limitada multiplicação do microrganismo (CHAVES-OLARTE et al., 2002).

$\mathrm{O}$ encontro de BCVs marcados com proteínas associadas a membrana lisossomal 1 (LAMP 1) e marcadores do retículo endoplasmático como calreticulina ou sec61 $\beta$, mas desprovidos de hidrolase lisossomal luminal como a catepsina D, confirmam a hipóste de que as brucelas trafegam de autofagossomos para o RE onde ocorre a sua multiplicação, e escape da sua inativação (PIZARRO-CERDÁ; MÉRESSE; PARTON, 1998). A sobrevivência intracelular nos macrófagos 
está ligada a inibição dos fagossomos que contém as brucelas e da fusão da membrana lisossomal (NAROENI et al., 2001; CELLI; CHASTELLIER; FRANCHINI, 2003). O operon virB e os mecanismos do T4SS regulam o tráfego intracelular do compartimento do autofagossomo até o RE (GORVEL; MORENO, 2002). O parasitismo da Brucella spp. não restringe as funções celulares básicas (CHAVES-OLARTE et al., 2002). As brucelas inibem a morte celular programada da célula infectada, bem como das células vizinhas (GROSS et al., 2000).

\section{Fatores de virulência}

Do interior dos macrófagos, sem ativar fortemente o sistema imune do hospedeiro as brucelas coordenam a expressão de múltiplos fatores de virulência relacionados a sua entrada e tráfego até ser atingido o seu nicho de replicação (RAMBOW-LARSEN et al., 2009). Diversos mecanismos reguladores da expressão gênica foram identificados no gênero Brucella: Quorum sensing, stringent response, sistema regulatório de dois componentes e, mais recentemente, o blue-light responsive LOV-HK protein, que é responsável pela adaptação das brucelas a diferentes ambientes (RAMBOW-LARSEN et al., 2009). O Quorum sensing no gênero Brucella coordena a expressão de genes em diferentes condições ambientais, como a produção do fator de necrose tumoral- $\alpha$ $(\mathrm{TNF}-\alpha)$. Devido a poucos nutrientes dentro do fagossomo, as brucelas dependem de seu regulador de stringent response que sintetiza transportadores periplasmáticos como nutrientes (LAMONTAGNE et al., 2009).

O sistema regulatório de dois componentes permite um ajuste individual da infecção e da expressão gênica em resposta ao estímulo ambiental. O sistema BvrR-BvrS (sistema regulatório de dois componentes) regula a fusão do fagolisossomo. $\mathrm{O}$ fator blue-light responsive LOV-HK protein também é utilizado pela Brucella spp., onde a exposição a luz aumenta a atividade enzimática sugerindo o aumento da virulência. As brucelas regulam a expressão de múltiplos fatores de virulência em resposta aos sinais moleculares acumulados via quorum sensitive system, e respondem a falta de nutrientes pela upregulation do T4SS via stringent system, enquanto o sistema de dois componentes contribui para a regulação dos genes OMPs, responsáveis pela divisão celular e aumento da virulência em resposta a luz (RAMBOW-LARSEN et al., 2009).

Tsolis et al. (2009) compararam o genoma de $B$. ovis com os genomas de B. suis, B. melitensis e $B$. abortus e constataram que no genoma de $B$. ovis faltavam os genes que codificam proteínas. Verificaram também que a $B$. ovis possui 33 genes codificantes de proteínas únicas para esta espécie. No cromossomo I de $B$. ovis falta a região que contém o gene wbo glycosyl transferase, considerado como essencial para a biossíntese do LPS. A ausência deste gene contribui para o fenótipo rugoso da linhagem. No cromossomo II, B. ovis contém uma ilha genômica única para a espécie de $26.5 \mathrm{~kb}$ chamada de $B$. ovis-pathogenicity island 1 (BOPI-1), que possui genes envolvidos com a patogênese como ORFs, ATP-Binding Cassete (ABC), transporter (abcABCDE) e um suposto gene da hemaglutinina $(h m g)$. A presença de pseudogenes está relacionada com a baixa virulência em humanos. $\mathrm{O}$ genoma de B. ovis possui 244 pseudogenes identificados (TSOLIS et al., 2009).

Nas fases iniciais da infecção o sistema de transporte $\mathrm{ABC}$ é requerido para a sobrevivência intra e extracelular da B. ovis (SILVA et al., 2011). Devido sua quantidade de pseudogenes a $B$. ovis codifica poucas proteínas do sistema de transporte ABC (TSOLIS et al., 2009), o que resulta na falha do transporte de certos nutrientes. Silva et al. (2011) ressaltaram que esta deficiência no transporte de nutrientes poderia ser a responsável pela completa ausência de virulência da $B$. ovis em certos animais. Nos testes de biotipagem, a $B$. ovis é urease negativa, entretanto, o seu genoma possui dois clusters de 
urease com mutações, deleções e pseudogenes que sugerem a inatividade do teste de urease. Isto justificaria o fato da infecção oral na brucelose ovina não ser importante, pois sendo urease negativa não sobrevive a passagem pelo estômago (BANDARA et al., 2007). Vários genes do metabolismo do açúcar que são funcionais nas espécies de Brucella spp. patogênicas para os humanos são incompletos na B. ovis (TSOLIS et al., 2009).

Sabe-se que o eritritol é uma fonte de carbono presente, na placenta de bovideos, suideos e caprinos que funciona como substância atrativa, respectivamente para $B$. abortus, $B$. suis e $B$. melitensis. Entretanto, a brucelose ovina possui baixa incidência de abortamentos. E a $B$. ovis não oxida o eritritol e também sua multiplicação não é inibida pela presença deste álcool. Isto é ocasionado devido ao stop codon no gene eryA e um frameshift no gene $e r y D$, que evita a entrada do eritritol na célula e impossibilita a sua utilização como fonte de carbono necessário para sua multiplicação. Estas limitações podem contribuir explicar a limitada virulência de B. ovis (TSOLIS et al., 2009).

Diversos transportadores $\mathrm{ABC}$ de açúcares possuem pseudogenes no genoma de $B$. ovis, que reduzem a sua habilidade para a utilização da glicose e da galactose. A B. ovis é a única espécie do gênero com fenótipo oxidase negativo dependente da atividade do gene citocromo oxidase $\mathrm{C}$, inativado em seu genoma. O metabolismo do nitrogênio da B.ovis é dependente de genes que codificam a produção da óxido nítro redutase, que estão ausentes no genoma de B. ovis, o que pode contribuir com o tropismo restrito para os tecidos, bem como, pela reduzida gama de hospedeiros (TSOLIS et al., 2009).

Os fatores responsáveis pela interação entre hospedeiro e patógeno podem ser sintetizados em quatro tópicos: LPS, T4SS, proteínas autotransportadoras e OMPs. A B. ovis possui um fenótipo rugoso de LPS. De fato sabe-se que o antígeno da cadeia $\mathrm{O}$ exerce uma função crítica na patogenicidade de $B$. abortus, $B$. suis e B. melitensis. $\mathrm{O}$ gene wboA ausente no genoma da $B$. ovis, bem como um pseudogene de glicoriltransferase que participa da biosíntese do LPS, outro pseudogene da família $\operatorname{LpxA}$ de aceiltransferase e uma suposta transferase que pode estar envolvida na biossíntese da mureína. Estas diferenças no LPS de B. ovis podem afetar a interação com toll-like-receptors (TLR) da resposta imune inata (TSOLIS et al., 2009).

O T4SS, codificado pelos genes virB1-virB12, é essencial para a virulência das linhagens de brucelas lisas (DELRUE et al., 2001). No genoma de $B$. ovis os genes virB1-virB12 estão intactos, o que indica que este sistema seja funcional nessa espécie (TSOLIS et al., 2009).

Admite-se que quatro proteínas estejam envolvidas no sistema de proteínas autotransportadoras das brucelas e que cada espécie do microrganismo codifica uma combinação de tais proteínas (CHAIN et al., 2005), o que indica que nenhuma das quatro proteínas é essencial para a virulência, mas que diferentes combinações das mesmas podem contribuir para o tropismo por tecidos bem como pela gama de hospedeiros suscetíveis a infecção por $B$. ovis. A proteína autotransportadora OmaA está ausente na $B$. ovis, aspecto que também contribui para o limitado tropismo por tecidos e pela gama de hospedeiros suscetíveis (TSOLIS et al., 2009). As OMPs são reguladas por dois components BvrR/BvrS, tidos como reguladores principais de várias funções de virulência que se encontram intactos no genoma de B. ovis (GUZMÁN-VERRI et al., 2001). Os dois genes omp $2 a$ e omp31 que codificam as OMPs possuem mutações na $B$. ovis, o que leva as OMPs de $B$. ovis a serem mais susceptíveis a pepitídeos catiônicos (FREER et al., 1999), comprometendo a estabilidade da célula e reduz a sua capacidade de sobrevivência r em ambientes desfavoráveis.

A biologia única de $B$. ovis se comparada com a das outras espécies patogênicas para os humanos 
se deve em parte ao resultado da degradação do seu genoma (TSOLIS et al., 2009). Além da importância da urease na infecção estabelecida pela via oral, também foi comprovado que esta enzima contribui para o estabelecimento da infecção pela via respiratória em suínos (BOSSE; MACINNES, 2000). Desta forma, possivelmente $B$. ovis não se estabelece no hospedeiro tanto pela via respiratória como pela via oral que são as duas principais vias de infecção das Brucellas patogênicas aos humanos (TSOLIS et al., 2009).

\section{Resposta imune}

Devido ao LPS pouco imunogênico que evade da detecção dos TLRs da resposta imune inata as brucelas induzem fraca resposta inflamatória nos hospedeiros infectados com conseqüente retardo em uma resposta imune efetiva (LAPAQUE; FORQUET; CHASTELLIER, 2006). A resposta inata ocorre imediatamente pelas PRRs que se ligam aos PAMPs bacterianos. TLRs, "nucleotidebinding oligomerization domain proteins” (NODs), "lipopolysaccharide binding protein" (LBP), MPR, são receptores eucarióticos que reconhecem os PAMPs (TIZARD, 2009). As brucelas produzem proteínas que inibem os sinais dependentes de TLRs, responsáveis pela maturação das células dendríticas (DC) e secreção de citocinas/quimiocinas inflamatórias com conseqüente interferência na resposta imune (R.I.) inata e adaptativa (SALCEDO; MAECHESINI; LELOUARD, 2008; CIRL; WIESER; YADAV, 2008). Quando as células de defesa (macrófagos, DC, mastócitos) são expostas aos PAMPs das bactérias mediante os receptores tipo PRRs via TLRs estas células secretam diversas proteínas, incluindo as citocinas, principalmente IL1a e TNF-a, assim como IL-6, IL-12 e IL-18 que desencadeiam uma resposta inflamatória da fase aguda (LAPAQUE; FORQUET; CHASTELLIER, 2006).

O bloqueio da produção de TNF-a também é uma atividade imuno-inibitória induzida pelas brucelas (BILLARD; DORNAND; GROSS, 2007). A ativação do complexo de TLRs pelas brucelas ocasiona a inibição da R.I. inata, secreção de citocinas, maturação de fagócitos, processamento de antígenos e apresentação de antígenos a LT (CIRL; WIESER; YADAV, 2008).

Em ovinos experimentalmente infectados com B. ovis estirpe PA Galindo et al. (2009), verificaram que até 60 dias pós-infecção havia o aumento da expressão (upregulation) de genes envolvidos com a ativação da resposta inflamatória e fagocitose. Também foi constatada a diminuição de expressão (downregulation) dos genes envolvidos com os mecanismos de proteção o que favoreceu a cronicidade do processo e a manutenção de um perfil de resposta imune celular (RIC) com linfócito T(LT) helper 1 (LTh1). De fato a natureza intracelular do agente estimula uma resposta imune celular do tipo linfócito T helper (RIC, LTh1) (VEMULAPALLI et al., 2000).

Os linfócitos T(LT) são diferenciados em duas classes: Th1 e Th2. A subclasse Th1 secreta principalmente IL-2, INF-g, TNF-a, que participam da RIC. A subclasse Th2 secretam IL-4, IL-5, IL-6, IL-10 promotoras da resposta imune humoral (RIH) (SALAS-TÉLLEZ et al., 2005). Ficht e Adams 2009. verificaram que tanto a resposta imune celular quanto a humoral participam na proteção contra a brucelose. A localização intracelular requer uma estimulação da RIC (Th1). Contudo, em camundongos foi demonstrado que a imunidade protetora contra brucelose é conseqüência de uma combinação entre anticorpos e RIC

Antunes (2012) analisando o perfil da expressão de citocinas em órgãos reprodutivos de carneiros por 240 dias após a infecção (dpi) com B. ovis (ATCC25840) contatou que, aos 30 dpi houve expressão aumentada das citocinas em epidídimos (IL-6, IL-1 $\beta$, IL-1 $\alpha$ ), testículos (INF- $\gamma$, IL-12), glândulas bulbouretrais (IL-6, TNF- $\alpha$ ) e nas ampolas (INF- $\gamma$, IL-10, IL-1 $\beta$, IL-1 $\alpha$ ), o que comprovou a indução da resposta imune pela $B$. 
ovis. Com o decorrer da infecção (60 dpi) houve um decréscimo na expressão de citocinas o que demonstrou a evasão da resposta imune, com exceção da observada nas glândulas bulbouretrais, o que favoreceu a persistência da $B$. ovis nesse orgão. Também foi observado que durante a fase crônica de infecção (120 e 240 dpi) a B. ovis induziu expressão menor das citocinas nos epidídimos (IL-1 $\beta$, IL$1 \alpha$ ), testículos (INF- $\gamma$, IL-12) e ampolas (INF- $\gamma$, IL-10, IL-1 $\beta$, IL-1 $\alpha$ ), com exceção das glândulas bulbouretrais (IL-6 and TNF- $\alpha$ ) e epidídimos (IL6) ainda numa tentativa de eliminação. Antunes (2012) destacou que a ativação da RI aos 30 dpi, com um decréscimo da expressão de citocinas e desenvolvimento da infecção, seria um mecanismo de escape da RI. No final da infecção foi constatada a existência de pequena ativação de citocinas Th1 e Th2, o que levou a conclusão de que a resposta imune celular e humoral seriam ineficazes para a eliminação do microrganismo. Este perfil de resposta imune demonstrado pela expressão gênica de citocinas é consequência da persistência da infecção.

\section{Conclusão}

A natureza intracelular do gênero Brucella estimula imunidade mediada por células, onde a resposta inflamatória moderada com padrão de citocinas inflamatórias é provavelmente o resultado da evasão e supressão da resposta imune dos hospedeiros. Na brucelose dos ovinos causada pela $B$. ovis, apesar da localização do agente ficar restrita aos tecidos do sistema reprodutor, os mecanismos e fatores de virulência utilizados para evasão da resposta imune são semelhantes aos empregados pelas outras espécies de brucelas nos seus respectivos hospedeiros preferenciais .

\section{Agradecimentos}

A Fundação de Amparo à Pesquisa do Estado de São Paulo (FAPESP 2008/03837-0, FAPESP 2008/03962-0).

\section{Referências}

ANTUNES, J. M. A. P. Perfil da expressão gênica induzida pela infecção experimental por Brucella ovis em tecidos reprodutivos e linfóides ovinos. 2012. Tese (Doutorado em Medicina Veterinária) - Faculdade de Medicina Veterinária e Zootecnia. Universidade Estadual Paulista, Botucatu.

ANTUNES, J. M. A. P.; ALlEDORF, S. D.; APPOLINÁRIO, C. M.; CAGNINI, D. Q.; FIGUEIREDO, P. R.; BURATINI JÚNIOR, J.; BAÑOS, J. V.; KOCAN, K. M.; DE LA FUENTE, J.; MEGID, J. Rough virulent strain of Brucella ovis induces pro- and anti-inflammatory cytokines in reproductive tissues in experimentally infected rams. Veterinary Microbiology, Utrecht, v. 161, n. 3-4, p. 339-43, 2013.

BANDARA, A. B.; CONTRERAS, A.; CONTRERASRODRIGUEZ, A.; MARTINS, A. M.; DOBREAN, V.; POFF-REICHOW, S.; RAJASEKARAN, P.; SRIRANGANATHAN, N.; SCHURIG, G. G.; BOYLE S. M. Brucella suis urease encoded by ure1 but not ure2 is necessary for intestinal infection of BALB/c mice. BMC Microbiology, Ames, v. 7, n. 7, p. 57, 2007.

BARNES, B.; LUBYOVA, B.; PITHA, P. M. On the role of IRF in host defense. Journal of Interferon Cytokine Research, New York, v. 22, n. 1, p. 59-71, 2009.

BELlAiRE, B. H.; ROOP, R. M.; CARDELLI, J. A. Opsonized virulent Brucella abortus replicates within nonacidic, endoplasmic reticulum-negative, LAMP-1positive phagosomes in human monocytes. Infection and Immunity, Washington, v. 3, n. 6, p. 3702-3713, 2005.

BIBERSTEIN, E. L.; MACGROWAN, B.; OLANDER, H.; KENNEDY, P. C. Epididymitis in rams. Studies on pathogenesis. Cornell Veterinary, Cornell, v. 57, n. 54, p. 2741, 1963.

BILLARD, E.; DORNAND, J.; GROSS, A. Brucella suis prevents human dendritic cell maturation and antigen presentation through regulation of tumor necrosis factor alpha secretion. Infection and Immunity, Washington, v. 75, n. 10, p. 4980-4989, 2007.

BOSSE, J. T.; MACINNES, J. I. Urease activity may contribute to the ability of Actinobacillus pleuropneumoniae to establish infection. Canadian Journal of Veterinary Research, Ottawa, v. 64, n. 3, p. 145-150, 2000.

CAMPBELL, G. A.; ADAMS, L. G.; SOWA, B. A. Mechanisms of binding of Brucella abortus to mononuclear phagocytes from cows naturally resistant or susceptible to brucellosis. Veterinary Immunology and Immunopathology, Amherst, v. 41, n. 3-4, p. 295-306, 1994. 
CARO-HERNÁNDEZ， P.; FENÁNDEZ-LAGO, L.; MIGUEL, M. J.; MARTÍN-MARTÍN, A. I.; CLOECKART, A.; GRILLÓ, M. J.; VISCAIINO, N. Role of the Omp25/Omp31 family in outer membrane properties and virulence of Brucella ovis. Infection and Immunity, Washington, v. 75, n. 8, p. 4050-4061, 2007.

CASTANEDA-ROLDAN, E. I.; AVELINO-FLORES, F.; DALL'AGNOL, M.; FREER, E.; CEDILLO, L.; DORNAND, J.; GIRON, J. A. Adherence of Brucella to human epithelial cells and macrophages is mediated by sialic acid residues. Cellular Microbiology, Lausanne, v. 6, n. 5, p. 435-445, 2004.

CELLI, J.; DE CHASTELLIER C.; FRANCHINI, D. M. Brucella evades macrophage killing via VirB-dependent sustained interactions with the endoplasmic reticulum. Journal of Experimental Medicine, Rockefeller, v. 198, n. 4, p. 545-556, 2003.

CHAIN, P. S.; COMERCI, D. J.; TOLMASKY, M. E.; LARIMER, F. W.; MALFATTI, S. A.; VERGEZ, L. M.; AGUERO, F.; LAND.; M. L.; UGALDE, R. A.; GARCIA, E. Whole-genome analyses of speciation events in pathogenic Brucellae. Infection and Immunity, Washington, v. 73, n. 12, p. 8353-8361, 2005.

CHAVES-OLARTE, E.; GUZMÁN-VERRI, C.; MÉRESSE, S.; DESJARDINS, M.; PIZARRO-CERDÁ, J.; BADILLA, J.; GORVEL, J.; MORENO, E. Activation of Rho and Rab GTPases dissociates Brucella abortus internalization from intracellular trafficking. Cellular Microbiology, Lausanne, v. 4, n. 10, p. 663-76, 2002.

CIRL, C.; WIESER, A.; YADAV, M. Subversion of Tolllike receptor signaling by a unique family of bacterial Toll/interleukin-1 receptor domain-containing proteins. Nature Medicine, v. 14, n. 4, p. 399-406, 2008.

COMERCI, D. J.; MARTINEZ-LORENZO, M. J.; SIEIRA, R.; GORVEL, J. P.; UGALDE, R. A. Essential role of the VirB machinery in the maturation of the Brucella abortus-containing vacuole. Cellular Microbiology, Lausanne, v. 3, n. 3, p. 159-168, 2001.

DELRUE, R. M.; MARTINEZ-LORENZO, M.; LESTRATE, P.; DANESE, I.; BIELARZ, V.; MERTENS, P.; DE BOLLE, X.; TIBOR, A.; GORVEL, J. P.; LETESSON, J. J. Identification of Brucella spp. genes involved in intracellular trafficking. Cellular Microbiology, Lausanne, v. 3, n. 7, p. 487-497, 2001.

ENRIGHT, F. M. The pathogenesis and pathobiology of infection in domestic animals. In: NIELSEN, K.; DUNCAN, J. R. (Ed.). Animal brucellosis: Florida, USA: CRC Press, Boca Ratón, 1990. p. 301-320.
ETTEMA, T. J.; ANDERSSON, S. G. The alphaproteobactéria: the Darwin finches of the bacterial world. Biology Letters, Great Britain, v. 5, n. 3, p. 429-432, 2009.

FERRAZ, I. B. F. Novos métodos de controle e diagnóstico da brucelose bovina. Revista Brasileira de Reprodução Animal, Belo Horizonte, v. 23, n. 4, p. 504508, 1999.

FICHT, T. A.; ADAMS, G. Vaccines for biodefense and emerging and neglected diseases. In: BARRETT, A. D. T.; STANBERRY, L. R. (Ed.). Brucellosis. Amsterdan: CRC Press, 2009. cap. 42, p. 807-29.

FOSTER, G.; MACMILLAN, A. P.; GODFROID, J.; HOWIE, F.; ROSS, H. M.; CLOECKAERT, A.; REID, R. J.; BREW, S.; PATTERSON, I. A. A review of Brucella sp. Infection of sea mammals with particular emphasis on isolates from Scotland. Veterinary Microbiology, Utrecht, v. 90, n. 1-4, p. 563-580, 2002.

FREER, E.; PIZARRO-CERDA, J.; WEINTRAUB, A.; BENGOECHEA, J. A.; MORIYON, I.; HULTENBY, K.; GORVEL, J. P.; MORENO, E. The outer membrane of Brucella ovis shows increased permeability to hydrophobic probes and is more susceptible to cationic peptides than are the outer membranes of mutant rough Brucella abortus strains. Infection and Immunity, Washington, v. 67, n. 11, p. 6181-6186, 1999.

GALINDO, R. C.; MUÑOZ, P. M.; DE MIGUEL, M. J.; MARIN, C. M.; BLASCO, J. M.; GORTAZAR, C.; KOCAN, K. M.; DE LA FUENTE, J. Differential expression of inflammatory and immune response genes in rams experimentally infected with a rough virulent strain of Brucella ovis. Veterinary Immunology and Immunopathology, v. 127, n. 3-4, p. 295-303, 2009.

GANZ, T.; LEHRER, R. I. Antimicrobial peptides of vertebrates. Current Opinion Immunology, Boston, v. 10, n. 1, p. 41-44, 1998.

GIL-TURNES, C. Brucelose ovina. In: CORREA, R. F.; SCHILD, A. L.; MENDEZ, M. C. (Ed.). Doencças de ruminantes e equinos. Pelotas: Editora da Universidade Federal de Pelotas, 1998. p. 161-169.

GORVEL, J. P.; MORENO, E. Brucella intracellular life: from invasion to intracelullar replication. Veterinary Microbiology, Utrecht, v. 90, n. 1-4, p. 281-297, 2002.

GROSS, A.; TERRAZA, A.; OUAHRANI-BETTACHE, S.; LIAUTARD, J. P.; DORNAND, J. In vitro Brucella suis infection prevents the programmed cell death of human monocytic cells. Infection and Immunity, Washington, v. 68, n. 1, p. 342-351, 2000. 
GUZMÁN-VERRI, C.; CHAVES-OLARTE, E.; VON EICHEL-STREIBER, C.; LÓPEZ-GOÑI, I.; THELESTAM, M.; ARVIDSON, S.; GORVEL, J. P.; MORENO, E. GTPases of the family Rho are required for Brucella abortus internalization in non professional phagocytes: direct activation of CDC42. The Journal of Biological Chemistry, v. 276, n. 48, p. 44435-44443, 2001.

LAMONTAGNE, A.; FOREST, E.; MARAZZO, F.; DENIS, H.; BUTLER, J. F.; MICHAUD, L.; BOUCHER, I.; PEDRO, A.; VILLENEUVE, D.; SITNIKOV, K.; TRUDEL, N.; NASSIF, D.; BOUDJELTI, F.; TOMAKI, E.; CHAVES-OLARTE, C.; GUZMAN-VERRI, S.; BRUNET, A.; COTE-MARTIN, J.; HUNTER, E.; MORENO, E.; PARAMITHIOTIS, E. Intracellular adaptation of Brucella abortus. Journal of Proteome Research, Washington, v. 8, n. 3, p. 1594-1609, 2009.

LAPAQUE, N.; FORQUET, F.; DE CHASTELLIER, C. Characterization of Brucella abortus lipopolysaccharide macrodomains as mega rafts. Cellular Microbiology, Lausanne, v. 8, n. 2, p. 197-206, 2006.

LIRA, N. S. C. Estudo da patogenia da brucelose em carneiros infectados experimentalemente com Brucella ovis REO 198. 2008. Tese (Doutorado em Medicina Veterinária) - Faculdade de Medicina Veterinária e Zootecnia. Universidade Estadual Paulista Júlio de Mesquita Filho, Botucatu.

LIRA, N. S. C.; MEGID, J. Patogenia da brucelose ovina. Veterinária e Zootecnia, Botucatu, v. 12, n. 2, p. 280-289, 2009.

LOPEZ, J.; BEST, A.; MORALEZ, C. Diagnóstico de brucelosis bovina en leche por el ring test y ELISA en lecherías de la provincia de Nuble (VIII Región). Archivos de Medicina Veterinaria, Valdivia, v. 30, n. 1, p. 133-138, 1998.

MARTÍN-MARTÍN, A.; CARO-HERNÁNDEZ, P.; ORDUNA, A.; VIZCAÍNO, N.; FERNANDEZ-LAGO, L. Importance of the Omp25/Omp31 family in the internalization and intracellular replication of virulent $B$. ovis in murine macrophages and HeLa cells. Microbes and Infection, Merced, v. 10, n. 6, p. 706-710, 2008.

MARTÍN-MARTIIN, A.; VIZCAÍNO, N.; FERNÁNDEZLAGO, L. Cholesterol, ganglioside GM1 and class A scavenger receptor contribute to infection by Brucella ovis and Brucella canis in murine macrophages. Microbes and Infection, Merced, v. 12, n. 3, p. 246-251, 2010.

NAROENI, A.; JOUY, N.; OUAHRANI-BETTACHE, S.; LIAUTARD, J. P.; PORTE, F. Brucella suis-impaired specific recognition of phago- somes by lysosomes due to phagosomal membrane modifications. Infection and Immunity, Washington, v. 69, n. 1, p. 486-493, 2001.
NOZAKI, C. N. Aspectos epidemiológicos, clínicos $e$ avaliação dos métodos diagnósticos nas diferentes fases de evolução da brucelose em ovinos inoculados experimentalmente com Brucella ovis. 2008. Tese (Doutorado em Medicina Veterinária) - Faculdade de Medicina Veterinária e Zootecnia. Universidade Estadual Paulista Júlio de Mesquita Filho, Botucatu.

NOZAKI, C. N.; LIRA, N. S. C.; AUGUSTO FILHO, O.; AZEVEDO, H. C.; RODELLO, L.; DASSO, M. G.; BICUDO, S. D.; ANTUNES, J. M. A. P.; MEGID, J. Rapid serum agglutination and agar gel immunodiffusion tests associated to clinical signs in rams experimentally infected with Brucella ovis. Ciência Rural, Santa Maria, v. 41, n. 8, p. 1441-1446, 2011a.

NOZAKI, C. N.; MEGID, K. C.; SILVA JUNIOR, F. F.; VELOSO, C. S. Comparação das técnicas de imunodifusão em gel de ágar e ELISA no diagnóstico de brucelose ovina em cabanhas da região centro-oeste do estado de São Paulo. Arquivos do Instituto Biológico, São Paulo, v. 71, n. 1, p. 1-5, 2004.

NOZAKI, C. N.; SALGADO, V. R.; LIRA, N. S. C.; AUGUSTO FILHO, O.; DASSO, M. G.; ANTUNES, J. M. A. P.; MEGID, J. Adaptation and evaluation of polymerase chain reaction for Brucella ovis detection in semen, urine and organs of rams experimentally infected. Arquivos Brasileiros de Medicina Veterinária e Zootecnia, Belo Horizonte, v. 63, n. 6, p. 1591-1594, $2011 b$.

PEI, J.; TURSE, J. E.; WU, Q.; FICHT, T. A. Brucella abortus rough mutants induce macrophage oncosis that requires bacterial protein synthesis and direct interaction with the macrophage. Infection and Immunity, Washington, v. 74, n. 5, p. 2667-2675, 2006.

PIZARRO-CERDÁ, J.; MÉRESSE, S.; PARTON, R. G. Brucella abortus transits through the autophagic pathway and replicates in the endoplasmic reticulum of nonprofessional phagocytes. Infection and Immunity, Washington, v. 66, n. 12, p. 5711-5724, 1998.

QIN, Q. M.; PEI, J.; ANCONA, V.; SHAW, B. D.; FICHT, T. A.; DE FIGUEIREDO, P. RNAi screen of endoplasmic reticulum-associated host factors reveals a role for IRE1alpha in supporting Brucella replication. PLoS Pathogens, San Francisco, v. 4, n. 7, p. e1000110, 2008.

RAJASHEKARA, G.; ESKRA, L.; MATHISON, A.; PETERSEN, E.; YU, Q.; HARMS, J.; SPLITTER, G. Brucella: functional genomics and host-pathogen interactions. Animal Health Research Reviews, v. 7, n. 1-2, p. 1-11, 2006. 
RAMBOW-LARSEN, A. A.; PETERSEN, E. M.; GOURLEY, C. R.; SPLITTER, G. A. Brucella regulators: self-control in a hostile environment. Trends in Microbiology, v. 17, n. 8, p. 371-377, 2009.

RIDLER, A. L.; WEST, D. M. Control of Brucella ovis infection in sheep. Veterinary Clinics of North America: Food Animal Practice, Philadelphia, v. 27, n. 1, p. 61-66, 2011.

RITTING, M. G.; ALVAREZ-MARTINEZ, M. T.; PORTE, F.; LIAUTARD, J. P.; ROUOT, B. Intracellular survival of Brucella spp. in human monocytes involves conventional uptake but special phagosomes. Infection and Immunity, Washington, v. 69, n. 6, p. 3995-4006, 2001.

SALAS-TÉLLEZ, E.; ARCO, N.; TENORIO, V.; DÍAZAPARICIO, E.; GARZA, M.; SUÁREZ-GUEMES, F. Subcellular fractions of Brucella ovis distinctively induce the production of interleukin-2, interleukin-4 and interferon-gamma in mice. The Canadian Journal of Veterinary Research, Ottawa, v. 69, n. 1, p. 53-57, 2005.

SALCEDO, S. P.; MAECHESINI, M. I.; LELOUARD, $\mathrm{H}$. Brucella control of dendritic cell maturation is dependent on the TIR-containing protein Btp1. PLoS Pathogens, San Francisco, v. 4, n. 2, p. e21, 2008.

SCHOLZ, H. C.; NOCKLER, K.; GOLLNER, C.; BAHN, P.; VERGNAUND, G.; TOMASO, H.; AL DAHOUK, S.; KAMPFER, P.; CLOECKAERT, A.; MAQUART, M.; ZYGMUNT, M. S.; WHATMORE, A. M.; PFEFFER, M.; HUBER, B.; BUSSE, H.J .; DE, B. K. Brucella microti sp. nov., isolated from the common vole Microtus arvalis. International Journal of Systematic and Evolutionary Microbiology, England, v. 58, n. 2, p. 375-382, 2008.

SCHOLZ, H. C.; HUBALEK, Z.; SEDLÁCEK, I.; VERGNAUD, G.; TOMASO, H.; AL DAHOUK, S.; MELZER, F.; KAMPFER, P.; NEUBAUER, H.; CLOECKAERT, A.; MAQUART, M.; ZYGMUNT, M. S.; WHATMORE, A. M.; FALSEN, E.; BAHN, P.; GOLLNER, C.; PFEFFER, M.; HUBER, B.; BUSSE, H. J.; NOCKLER, K. Brucella inopinata sp. nov., isolated from a breast implant infection. International Journal of Systematic and Evolutionary Microbiology, England, v. 60, n. 4, p. 801-808, 2010.

SELEEM, M. N.; BOYLE, S. M.; SRIRANGANATHAN, N. Brucella: a pathogen without classic virulence genes. Veterinary Microbiology, Utrecht, v. 129, n. 1-2, p. 1-14, 2008.

SILVA, T. M.A.; PAIXÃO, T.A.; COSTA, E.A.; XAVIER, M. N.; SÁ, J. C.; MOUSTACAS, V. S.; HARTIGH, A. B.; NETA, A. V. C.; OLIVEIRA, S. C.; TSOLIS, R.; SANTOS, R. L. Putative ATP-Binding Cassette
Transporter is Essential for Brucella ovis Pathogenesis in Mice. Infection and Immunity, Washington, v. 79, n. 4, p. 1706-1, 2011.

TALESKI, V.; ZERVA, L.; KANTARDJIEV, T.; CVETNIC, Z.; ERSKI-BILJIC, M.; NIKOLOVSKI, B.; BOSNJAKOVSKI, J.; KATALINIC-JANKOVIC, V.; PANTELIADOU, A.; STOJKOSKI, S.; KIRANDZISKI, T. An overview of the epidemiology and epizootology of brucellosis in selected countries of Central and Southeast Europe. Veterinary Microbiology, Utrecht, v. 90, n. 1-4, p. 147-55, 2002.

TILLER, R. V.; GEE, J. E.; LONSWAY, D. R.; GRIBBLE, S.; BELL, S. C.; JENNISON, A.V.; BATES, J.; COUlTER, C.; HOFFMASTER, A. R.; DE, B. K. Identification of an unusual Brucella strain (BO2) from a lung biopsy in a 52 year-old patient with chronic destructive pneumonia. BMC Microbiology, London, v. 10, p. 1-11, 2010.

TIZARD, I. R. Imunologia veterinária. 8. ed. Rio de Janeiro: Saunders Elsevier, 2009. 587 p.

TSOLIS, R. M.; SESHADRI, R.; SANTOS, R. L.; SANGARI, F. J.; LOBO, J. M. G.; JONG, M. F.; REN, Q.; MYERS, G.; BRINKAC, L. M.; NELSON, W. C.; DEBOY, R. T.; ANGUOLI, S.; KHOURI, H.; DIMITROV, G.; ROBINSON, J. R.; MULLIGAN, S.; WALKER, R. L.; ELZER, P. E.; HASSAN, K. A.; PAULSEN, I. T. Genome degradation in Brucella ovis Corresponds with narrowing of its host range and tissue tropism. PLoS ONE, San Francisco, v. 4, n. 5, p. e5519, 2009.

VEMULAPALLI, R.; HE, Y.; BOYLE, S. M.; SRIRANGANATHAN, N.; SCHURIG, G. G. Brucella abortus strain RB51 as a vector for heterologous protein expression and induction of specific Th1 type immune responses. Infection and Immunity, Washington, v. 68, n. 6, p. 3290-3296, 2000.

VISCAÍNO, N.; KITTELBERGER, R.; CLOECKAERT, A.; MARÍN, C. M.; FERNÁNDEZ-LAGO, L. Minor nucleotide substitutions in the omp31 gene of Brucella ovis result in antigenic differences in the major outer membrane protein that it encodes compared to those of the other Brucella species. Infection and Immunity, Washington, v. 69, n. 11, p. 7020-7028, 2001.

XAVIER, M. N.; SILVA, T. M. A.; COSTA, E. A.; PAIXÃO, T. A.; MOUSTACAS V. S.; CUSTÓDIO, A.; CARVALHO-JÚNIOR, A.; SANTANNA, F. M.; ROBLES, C. A.; GOUVEIA, A. M. G.; LAGE, A. P.; TSOLIS, R. M.; SANTOS, R. L. Development and evaluation of a species-specific PCR assay for the detection of Brucella ovis infection in rams. Veterinary Microbiology, Utrecht, v. 145, n. 1-2, p. 158-64, 2010. 